\title{
casa de plástico, en Francia
}

LIONEL SCHEIN, arquitecto

YVES MAGNANT, problemas fécnicos

\section{SINOPSIS}

*He recogido esta caracola

de entre la arena. No se me ofrecía

como un algo informe, sino

como un algo todas cuyas partes

y facetas muestran una

interdependencia, una tan notable

continuidad una con otra,

y un acuerdo tal,

que pude, tras una simple ojeada,

concebir y prever las formas en su sucesión.

Estas facetas y estas partes

unidas por lazos que no son sólo

la cohesión y solidez de la materia.

Observaciones

todas que me llevan a pensar

en la fabricación de un caracol como posible».

(Paul Valery:

k'homme et la Coquille»).

Esta meditación sobre la estructura protectora de un organismo vivo

sirve de introducción conceptual al estudio de la vivienda evolutiva. A nadie escapará

la profunda analogia existente

entre las ideas, que han regido su concepción y realización y las que de la

exquisita prosa del pensador francés se desprenden. 


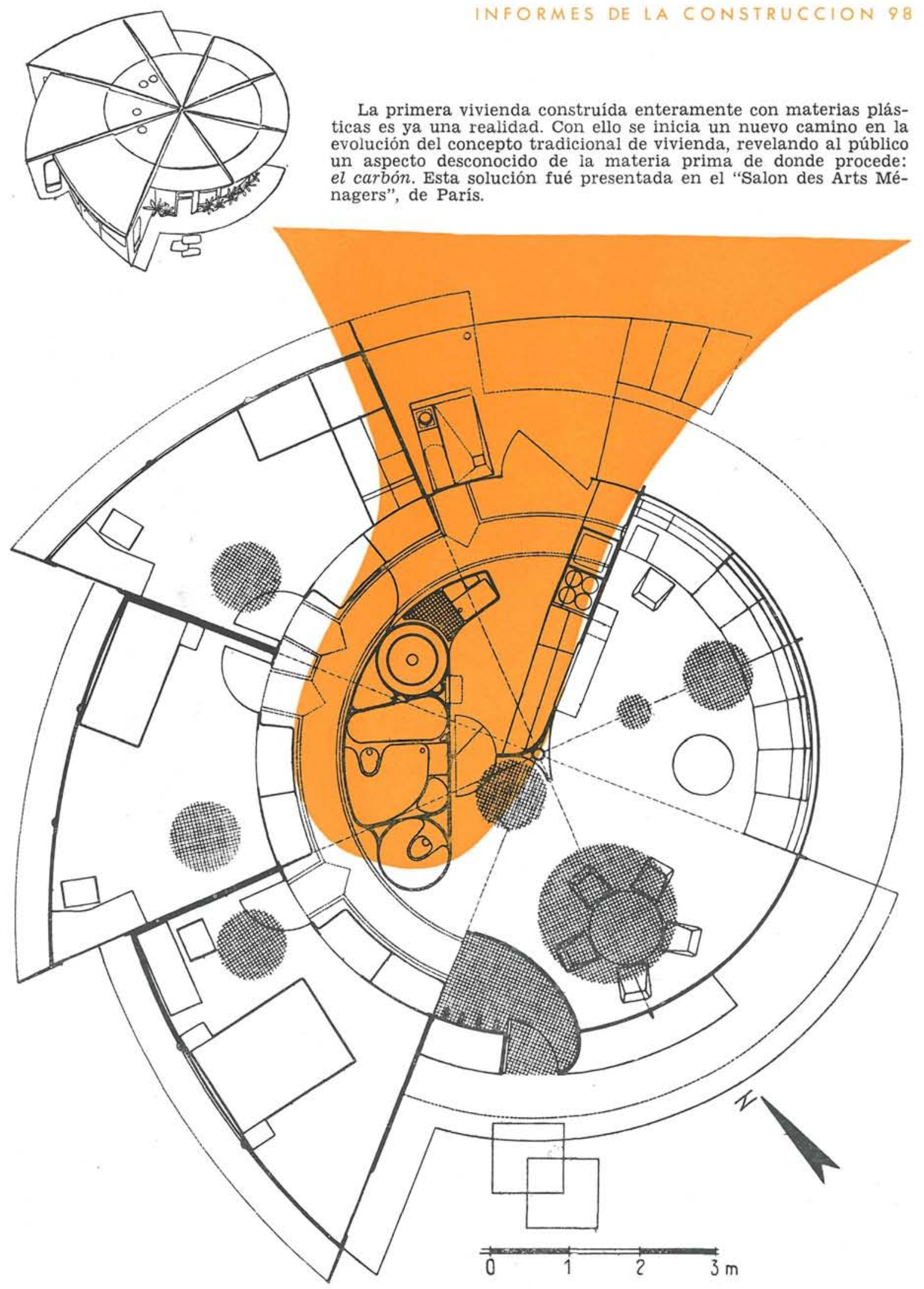

perspectiva y planta 


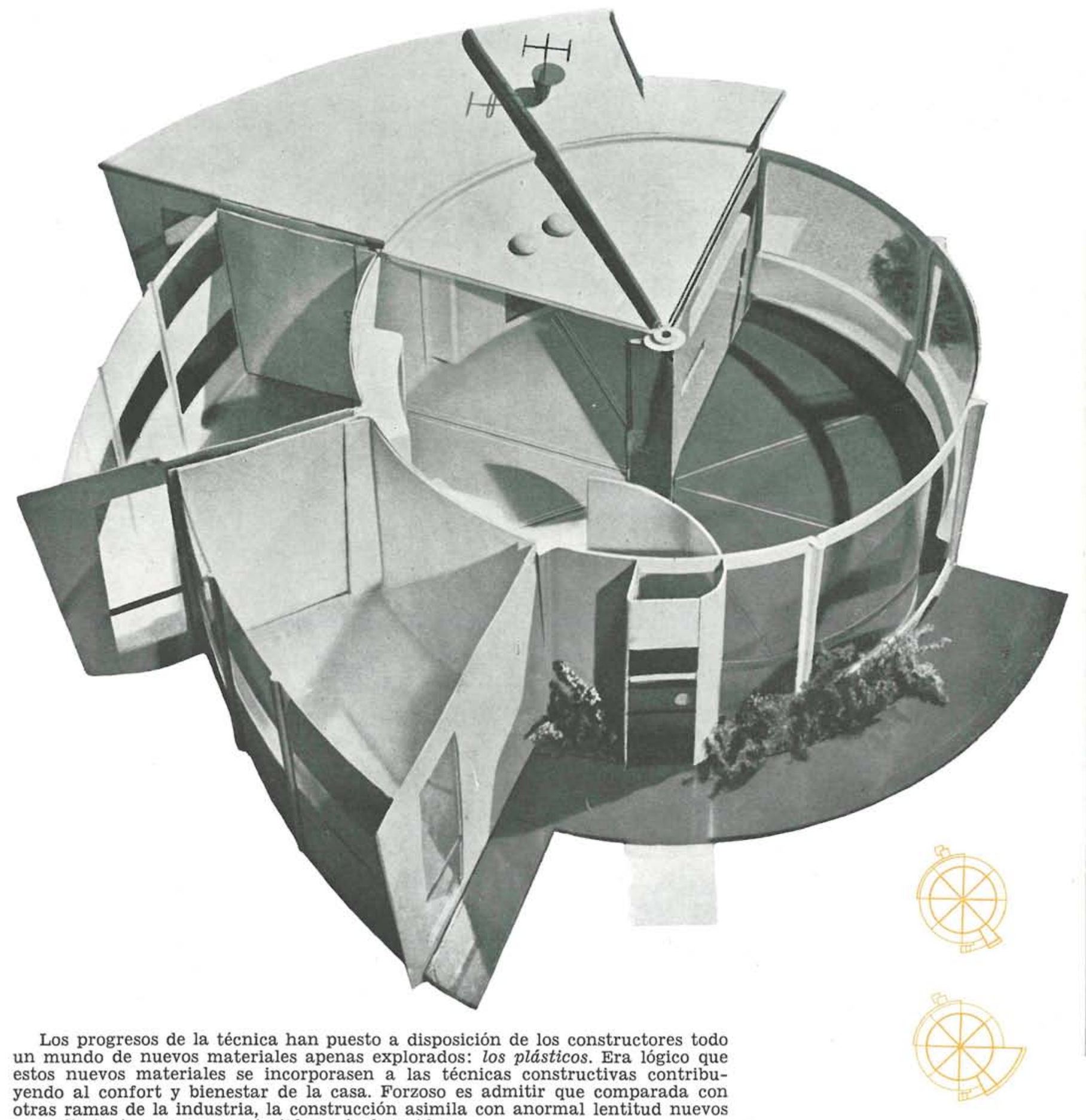
otras ramas de la industria, la construcción asimila con anormal lentitud nuevos procedimientos, nuevos materiales e incluso ideas.

En este caso, los arquitectos han tenido en cuenta en su proyecto los dos imperativos de toda nueva realización: respetar cuanto de "permanente" hay y adaptar cuanto de "evolutivo". Y han sabido encontrar para los elementos constructivos y equipo del hogar, formas adecuadas a la función y al material que las constituye; rebusca ésta de gran interés, en muchas otras ocasiones descuidada.

En atención a la facilidad de montaje y a la posibilidad de fabricación en serie, encierran estos ensayos la ilusión de llegar a encontrar una solución al problema de la vivienda y de la vida familiar, como etapa esencial en el camino de la felicidad, meta de la civilización.

Los plásticos permiten a la arquitectura usar un lenguaje revolucionario, innovador-como ya antes lo hizo el hormigón-, permitiendo el empleo de membranas,
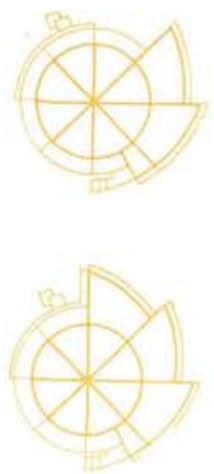


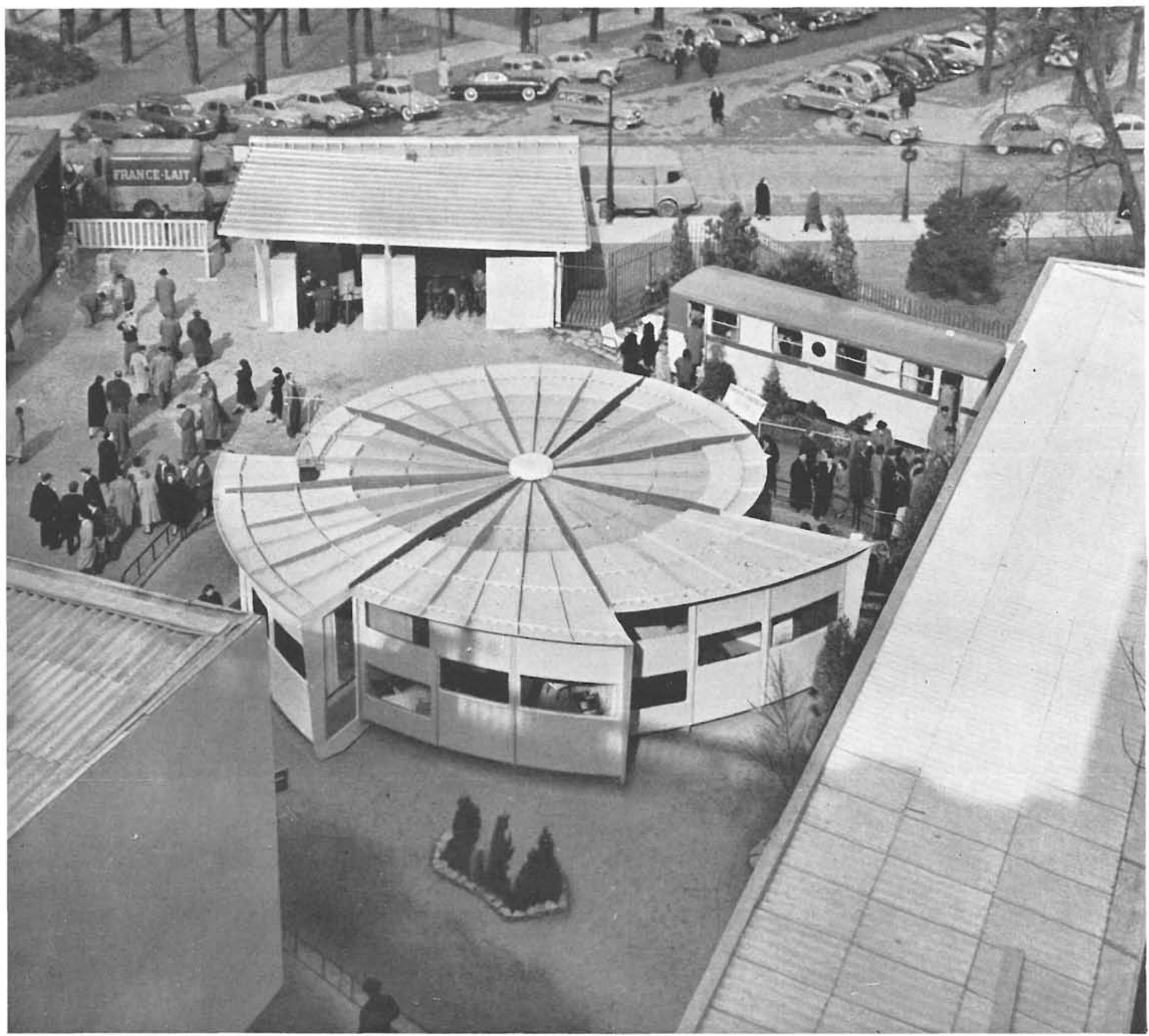

bóvedas, aletas... con facilidad asombrosa. La ortogonalidad deja de tener su antiguo significado. El peso desaparece o se aligera al disminuir las secciones, favoreciendo el empleo de composiciones flexibles; los volúmenes quedan definidos por verdaderas "carrocerías" del hogar para vivir o trabajar. Moldeando la vivienda y los edificios, el arquitecto pide prestado al escultor parte de su personalidad, tratando de conseguir resultados definitivos de estos balbuceos técnicos que ahora se inician. Las materias plásticas pueden, desde este momento, dar nombre a un estilo vegetal, biológico, creando en la arquitectura una revolución más importante que la ocasionada por la aparición del arco o la bóveda.

De entre la múltiple gama de plásticos-polyamidas, polyvinilos, polyésteres, etcétera-se han escogido aquellos cuya estratificación se produce a bajas presiones, con vistas a su fácil moldeo y por ser los únicos que permiten la cons- 
a liza dos

sección trucción de elementos resistentes de grandes dimensiones. Pueden igualmente realizarse con ellos múltiples estructuras de tipo "sandwich", en las que los materiales de relleno son derivados de los mismos. Poseen un conjunto de características de excepcional interés en la construcción: alta resistencia mecánica (el más alto coeflciente en la relación peso-resistencia); gran estabilidad e inercia química; buenas propiedades de aislamiento térmico y acústico; posibilidades de transformación y moldeo a baja temperatura y presión, y la ya indicada de $x$ u facilidad de adaptarse a las formas más complejas.

Las estructuras que con este material pueden realizarse quedan aisladas térmicamente por sí mismas, con espesores de sólo algunos centímetros. Su superficie es tibia al tacto como consecuencia de su gran inercia calorifica. Lo mismo ocurre con sus condiciones acústicas, y su conservación es menos costosa que la requerida por estructuras tradicionales, aportando al mismo tiempo mayor confort.
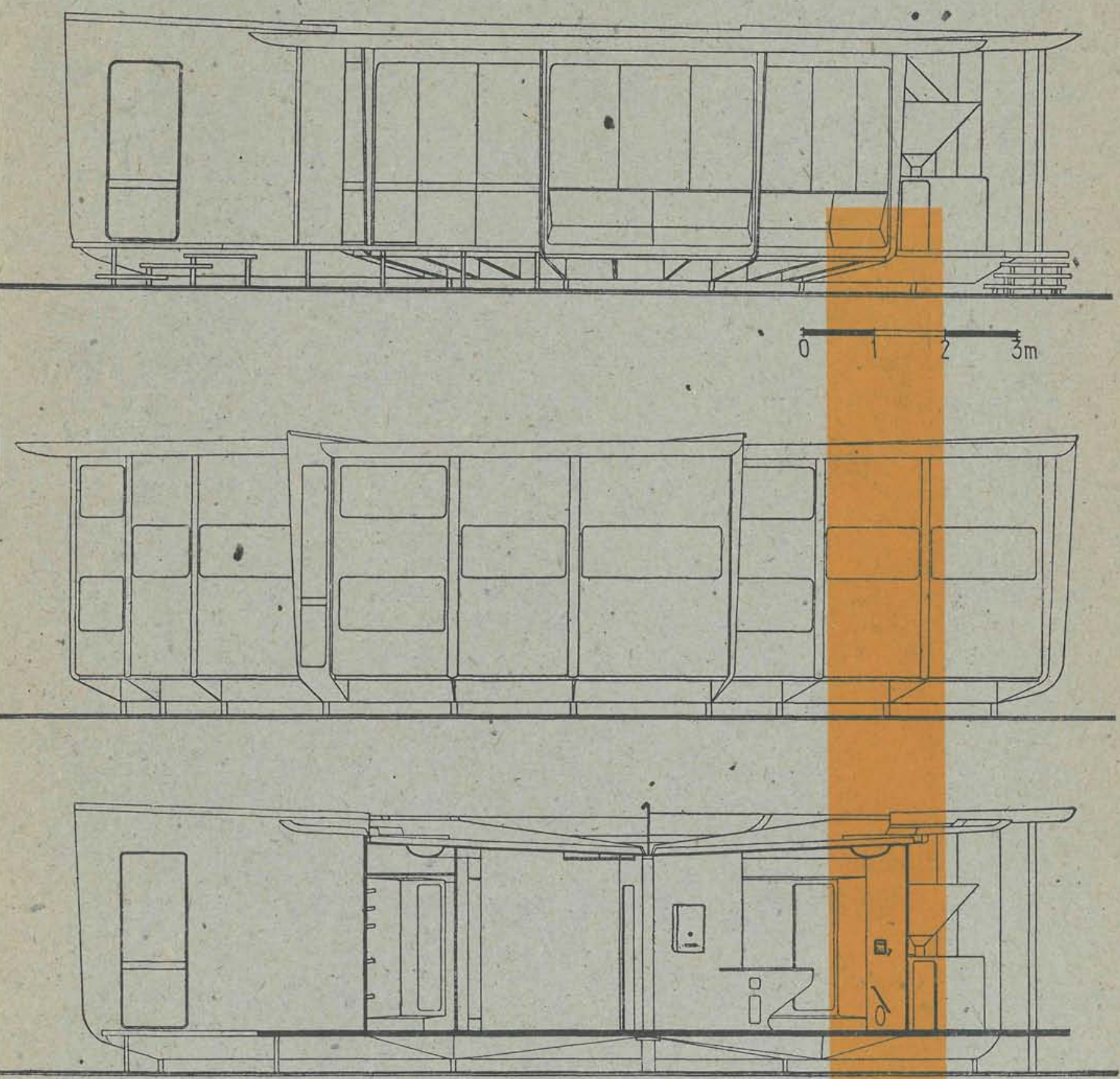


\section{bloque şanitario}
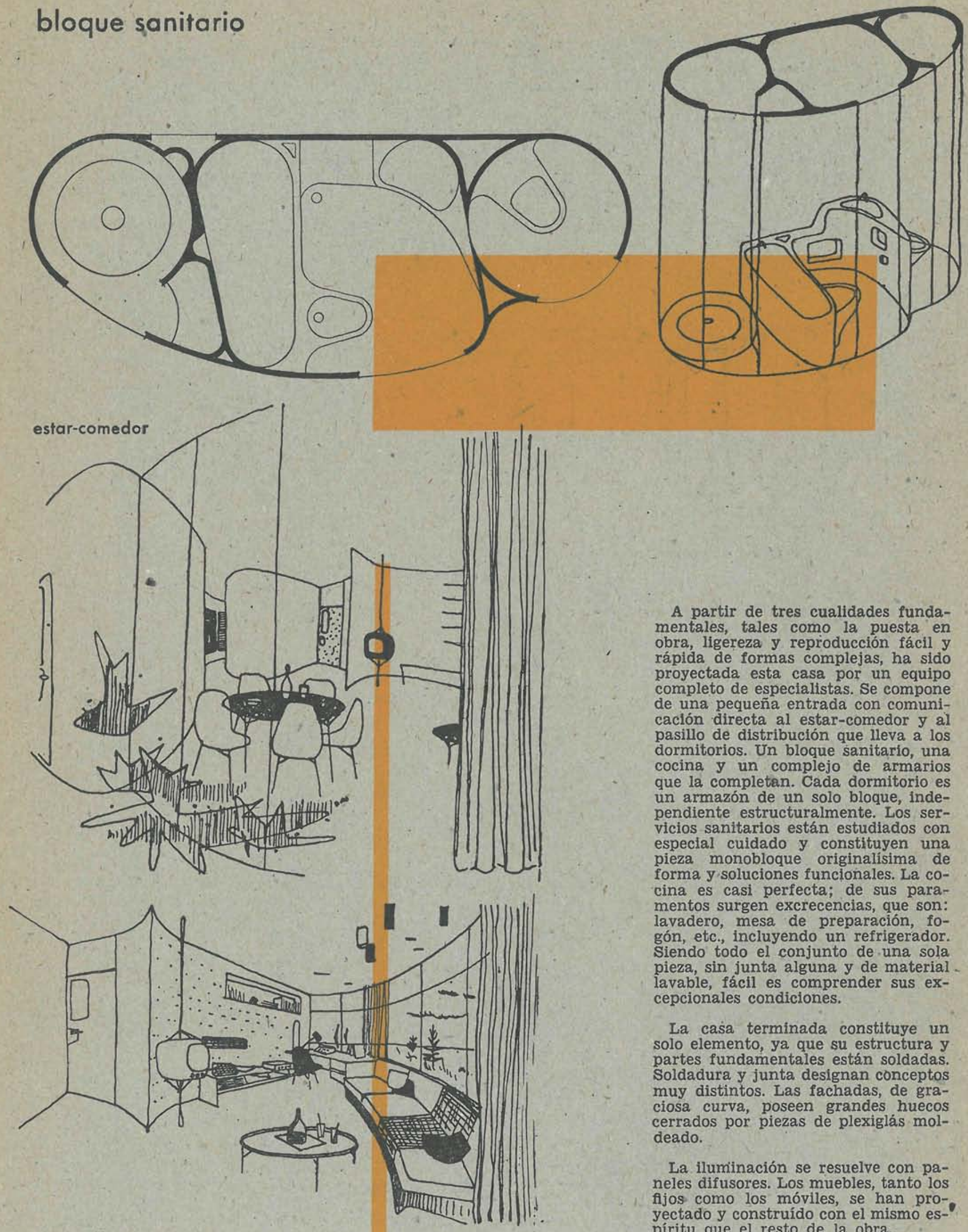

A partir de tres cualidades fundamentales, tales como la puesta en obra, ligereza y reproducción fácil y rápida de formas complejas, ha sido proyectada esta casa por un equipo completo de especialistas. Se compone de una pequeña entrada con comunicación directa al estar-comedor y al pasillo de distribución que lleva a los dormitorios. Un bloque sanitario, una cocina y un complejo de armarios que la completan. Cada dormitorio es un armazon de un solo bloque, independiente estructuralmente. Los servicios sanitarios están estudiados con especial cuidado y constituyen una pieza monobloque originalisima de forma y soluciones funcionales. La cocina es casi perfecta; de sus paramentos surgen excrecencias, que son: lavadero, mesa de preparación, fogón, etc., incluyendo un refrigerador. Siendo todo el conjunto de una sola pieza, sin junta alguna y de material lavable, fácil es comprender sus excepcionales condiciones.

La casa terminada constituye un solo elemento, ya que su estructura y partes fundamentales están soldadas. Soldadura y junta designan conceptos muy distintos. Las fachadas, de graciosa curva, poseen grandes huecos cerrados por piezas de plexiglás moldeado.

La fluminación se resuelve con paneles difusores. Los muebles, tanto los fijos como los móviles, se han proyectado y construído con el mismo espíritu que el resto de la obra. 
reparación del material
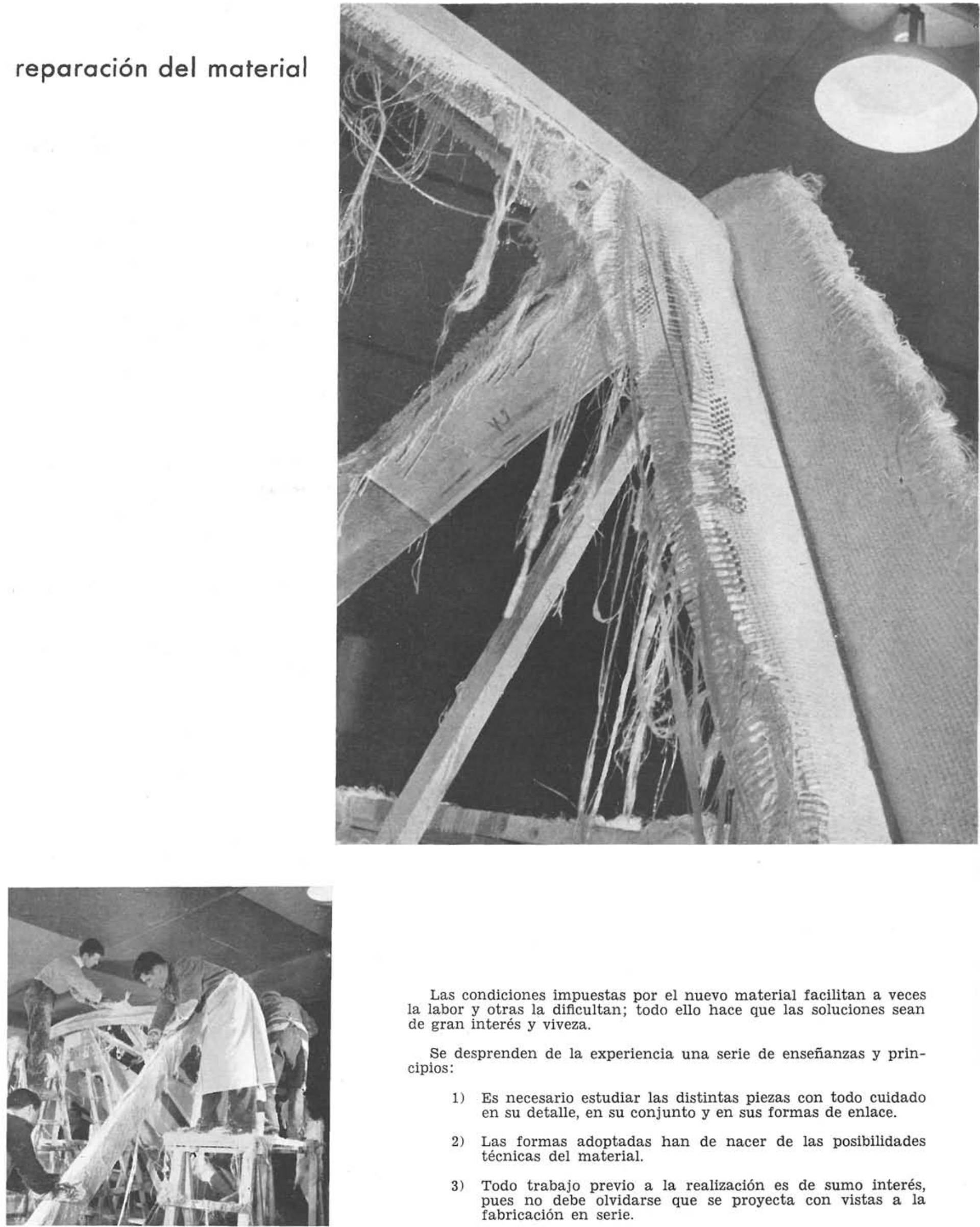

Las condiciones impuestas por el nuevo material facilitan a veces la labor y otras la dificultan; todo ello hace que las soluciones sean de gran interés y viveza.

Se desprenden de la experiencia una serie de enseñanzas y principios:

1) Es necesario estudiar las distintas piezas con todo cuidado en su detalle, en su conjunto y en sus formas de enlace.

2) Las formas adoptadas han de nacer de las posibilidades técnicas del material.

3) Todo trabajo previo a la realización es de sumo interés, pues no debe olvidarse que se proyecta con vistas a la fabricación en serie. 


$$
\text { fases sucesivas de la preparación }
$$
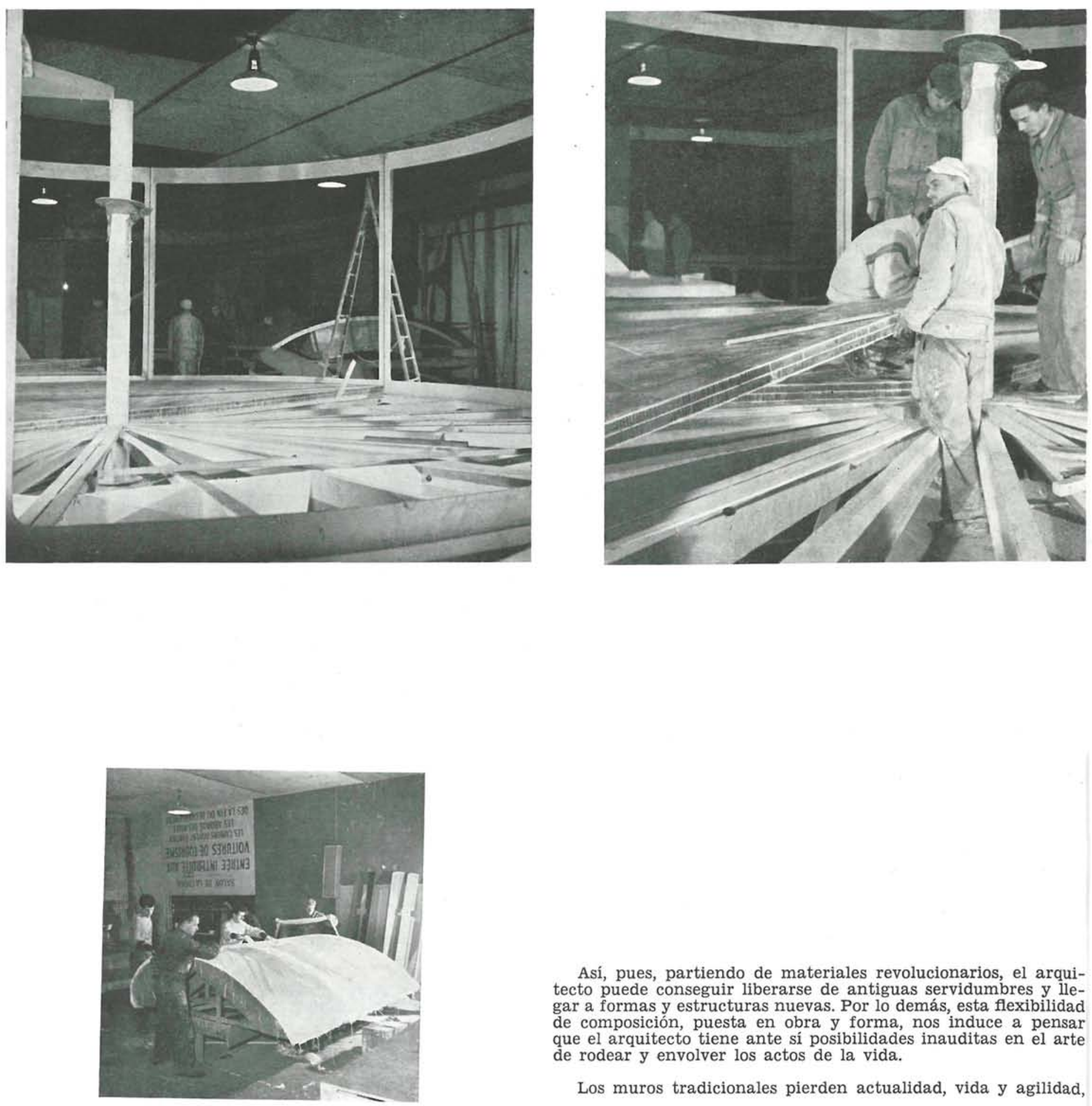

Así, pues, partiendo de materiales revolucionarios, el arquitecto puede conseguir liberarse de antiguas servidumbres y llegar a formas y estructuras nuevas. Por lo demás, esta flexibilidad de composición, puesta en obra y forma, nos induce a pensar que el arquitecto tiene ante sí posibilidades inauditas en el arte de rodear y envolver los actos de la vida.

Los muros tradicionales pierden actualidad, vida y agilidad, 


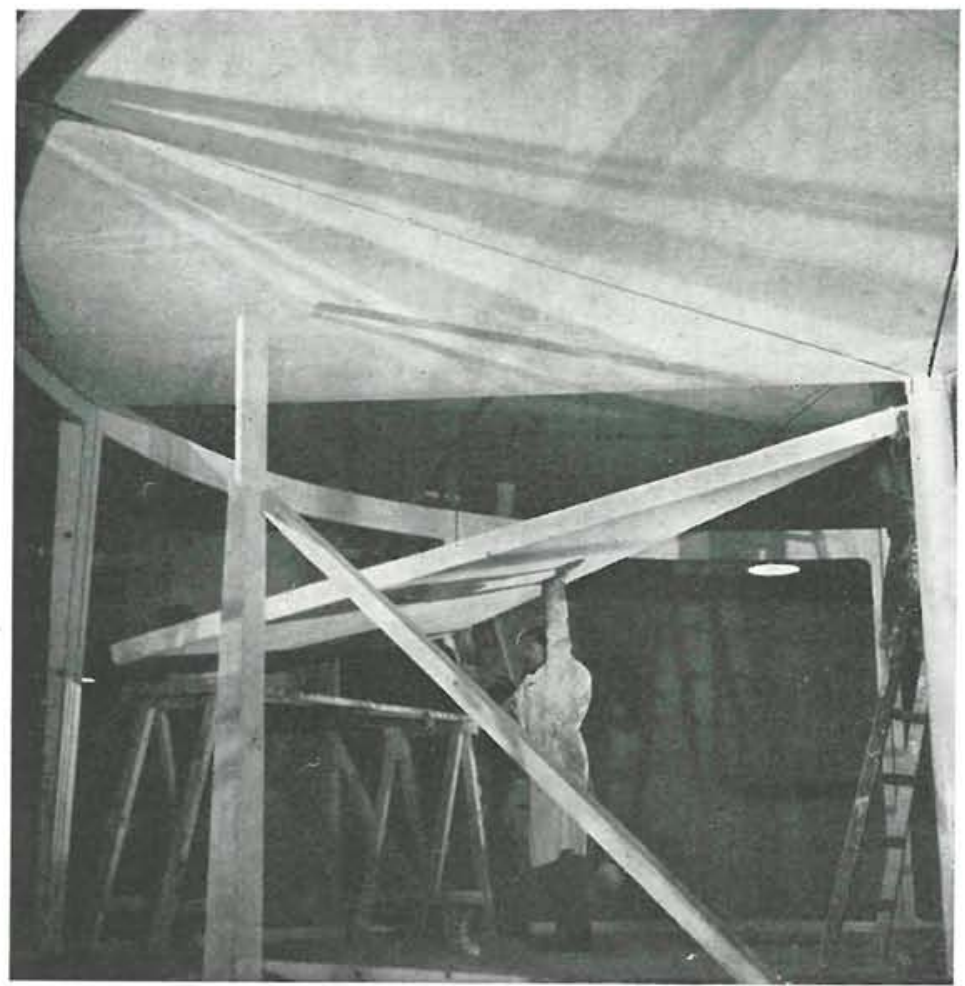

Fotosi SON ET LUMIERE Foto de corocolas M. GARCIA MOYA

mientras que la curva se hace más humana, más activa y más adaptable a las necesidades.

Como conclusión final señalemos que la casa cien por cien en plástico, es hija de nuestro tiempo, y representa una victoria contra la esclerosis existente en las mentes de las gentes reacias a ultranza a la evolución de las cosas y a la incorporación de los progresos técnicos a la vida diaria.
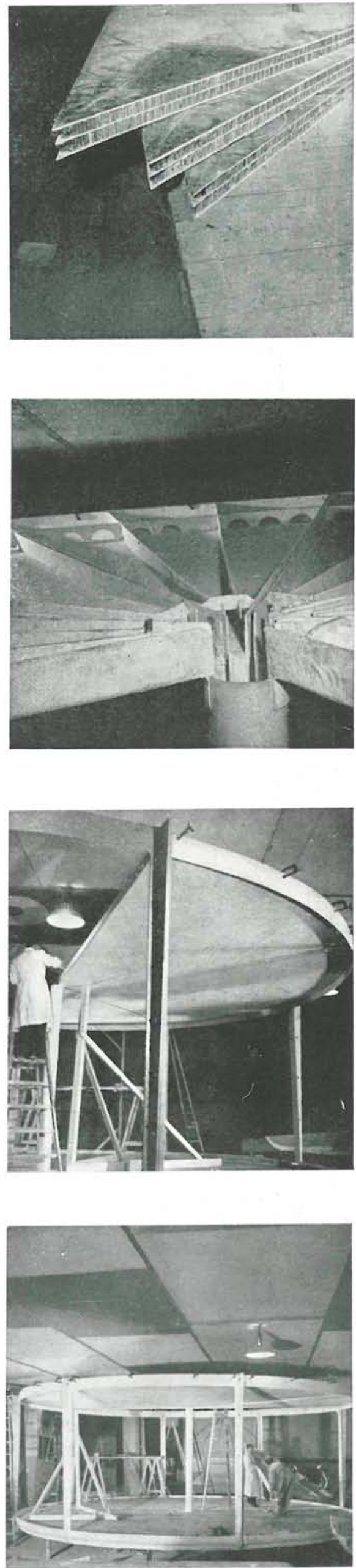